\title{
CRESCIMENTO, FOTOSSÍNTESE E ATIVIDADE ENZIMÁTICA DE GENÓTIPOS DE ALGODOEIRO HERBÁCEO SUBMETIDOS AO CLORETO DE MEPIQUAT
}

\author{
Amanda Pereira Paixão ${ }^{1}$, Enes Furlani Junior ${ }^{2}$, Simone Silva Hiraki ${ }^{3}$, Luis Henrique Marani \\ Daruichi Machado ${ }^{4}$, Liliane Santos de Camargos ${ }^{5}$, Fernando Tadeu de Carvalho ${ }^{6}$

\footnotetext{
${ }^{1}$ Doutoranda em Agronomia - Universidade Estadual Paulista (UNESP), Faculdade de Engenharia, Câmpus de Ilha Solteira - SP. E-mail: amandappaixao@yahoo.com.br .

${ }^{2}$ Professor Titular Doutor, Universidade Estadual Paulista (UNESP), Faculdade de Engenharia, Câmpus de Ilha Solteira - SP.

${ }^{3}$ Professora Doutora, Instituto Federal de Mato Grosso do Sul (IFMS), Câmpus de Ponta Porã - MS.

${ }^{4}$ Biólogo, Universidade Estadual Paulista (UNESP), Faculdade de Engenharia, Câmpus de Ilha Solteira - SP.

${ }^{5}$ Professora Assistente Doutora, Universidade Estadual Paulista (UNESP), Faculdade de Engenharia, Câmpus de Ilha Solteira - SP.

${ }^{6}$ Professor Adjunto, Universidade Estadual Paulista (UNESP), Faculdade de Engenharia, Câmpus de Ilha Solteira - SP.
}

RESUMO: Os genótipos de algodoeiro herbáceo FMT 701 e Fibermax 966 apresentam características morfofisiológicas distintas devido à sua constituição genética diferenciada, sendo assim é possível que possuam diferenças de resposta quanto à aplicação de doses crescentes de regulador vegetal, caracterizando a hipótese principal do presente estudo. $\mathrm{O}$ objetivo deste trabalho foi avaliar dois genótipos de algodoeiro com características genéticas distintas, os aspectos de crescimento, o aparato fotossintético e a atividade das enzimas antioxidantes em função da aplicação do regulador vegetal à base de cloreto de mepiquat. $\mathrm{O}$ experimento foi conduzido em casa de vegetação da UNESP, Ilha Solteira-SP, em Fevereiro de 2014, cujo delineamento experimental foi de blocos ao acaso, em esquema fatorial $5 \times 2$, totalizando 10 tratamentos, com 4 repetições, perfazendo um total de 40 vasos. O cloreto de mepiquat foi aplicado via foliar aos 50,60 e 70 dias após a emergência, cujos tratamentos foram quatro doses $\left(500 ; 1,000 ; 1,500\right.$; e $\left.2,500 \mathrm{~mL} \mathrm{ha}^{-1}\right)$ equivalentes ao estudo em vasos, e a testemunha. De posse dos resultados, verificou-se que a aplicação do regulador vegetal nos genótipos foi eficiente em termos de limitação de crescimento em altura, sendo o efeito mais positivo no FMT 701, e o genótipo Fibermax 966 exigiu menor uso do regulador. O cloreto de mepiquat influenciou alguns parâmetros fotossintéticos dos genótipos, sendo que estes apresentaram a mesma eficiência de assimilação do $\mathrm{CO}_{2}$. O regulador não influenciou o aparato fotoquímico, as características da fluorescência da clorofila $a$ e as enzimas antioxidantes dos genótipos, não desencadeando o estresse oxidativo.

Palavras-chave: Gossypium hirsutum L. var. latifolium Hutch. Regulador vegetal. Estresse oxidativo. Fluorescência da clorofila $a$.

\section{GROWTH, PHOTOSYNTHESIS AND ENZYMATIC ACTIVITY OF HERBACEOUS COTTON GENOTYPES SUBMITTED TO MEPIQUAT CHLORIDE}

Cultura Agronômica, Ilha Solteira, v.26, n.4, p.540-553, 2017 


\begin{abstract}
The genotypes of herbaceous cotton FMT 701 and Fibermax 966 have different morphophysiological characteristics due to their differentiated genetic constitution, so it is possible that they have different responses regarding the application of increasing doses of plant regulator, characterizing the main hypothesis of the present study. The objective of this work was to evaluate two cotton genotypes with different genetic characteristics, growth aspects, the photosynthetic apparatus and the activity of the antioxidant enzymes as a function of the application of the vegetal regulator based on mepiquat chloride. The experiment was conducted in a greenhouse at UNESP, Ilha SolteiraSP, in February 2014, with a randomized block design in a 5x2 factorial scheme, totaling 10 treatments, with 4 replicates, making a total of 40 vessels. Mepiquat chloride was applied in the leaves at 50, 60 and 70 days after emergence. The treatments were four doses $(500$, $1.000,1.500$ and $2.500 \mathrm{~mL} \mathrm{ha}^{-1}$ ) equivalent to the study in pots, and the control. Based on the results, it was verified that the application of the plant regulator in the genotypes was efficient in terms of limitation of growth in height, being the most positive effect in FMT 701, and the Fibermax 966 genotype required less use of the regulator. Mepiquat chloride influenced some photosynthetic parameters of the genotypes, which presented the same $\mathrm{CO}_{2}$ assimilation efficiency. The regulator did not influence the photochemical apparatus, the chlorophyll a fluorescence characteristics and the antioxidant enzymes of the genotypes, and did not trigger oxidative stress.
\end{abstract}

Key words: Gossypium hirsutum L. var. latifolium Hutch. Plant regulator. Oxidative stress. Chlorophyll $a$ fluorescence.

\title{
INTRODUÇÃO
}

O algodoeiro herbáceo (Gossypium hirsutum L. var. latifolium Hutch) é uma planta que possui alta complexidade morfológica e genética. Apresenta metabolismo fotossintético do tipo C3, com alta taxa de fotorrespiração, que pode ser superior a $40 \%$ da fotossíntese bruta, dependendo do ambiente, em especial luminosidade e a temperatura (TAIZ; ZEIGER, 2013).

Pelo fato do algodoeiro ser uma planta com hábito de crescimento indeterminado, busca-se com a utilização de reguladores vegetais uma limitação do crescimento vegetativo para que ocorra maior deslocamento de metabolitos para os drenos úteis do ponto de vista econômico (BELTRÃO et al., 1997).

Entre os reguladores vegetais mais utilizados na cotonicultura moderna brasileira, destaca-se o cloreto de mepiquat, comercialmente conhecido por PIX HC, que inibe a produção natural de giberelinas, reduzindo o crescimento vegetativo em excesso sem afetar a produtividade (REDDY et al., 1995). Segundo Fernandez (1991) há indícios que o regulador possa interferir nas trocas gasosas, modificando a taxa fotossintética de plantas de algodoeiro.

Cultura Agronômica, Ilha Solteira, v.26, n.4, p.540-553, 2017 
Não há relatos na literatura científica atual se a utilização de cloreto de mepiquat desencadeia o estresse oxidativo em genótipos de algodoeiro. Porém é sabido que as plantas quando em condições de estresse, alteram o seu metabolismo ocorrendo o aumento da produção de espécies reativas de oxigênio (EROs), radicais livres. Os mecanismos de defesa das plantas no processo de detoxificação de EROs é composto por um conjunto de enzimas antioxidantes, onde se destacam a superóxido dismutase (SOD), catalase (CAT) e a peroxidase (POD) (APEL; HIRT, 2004).

Segundo a Fundação MT (2012) o genótipo FMT 701 apresenta porte alto (1,70 m), possui ciclo médio tardio, sendo altamente responsiva e adaptada a colheita mecanizada, além de possuir boa qualidade de fibra. Por outro lado, de acordo com a Bayer CropScience (2012) o genótipo Fibermax 966 apresenta porte baixo (0,90 a 1,20 m), ciclo precoce, fibra com ótima qualidade e rendimento industrial e menor uso de regulador de crescimento.

Objetivou-se com o presente trabalho estudar o crescimento, o aparato fotossintético, bem como a atividade das enzimas antioxidantes dos genótipos de algodoeiro herbáceo FMT 701 e Fibermax 966, com características genéticas distintas, em função da aplicação de doses crescentes de cloreto de mepiquat, através de analises fisiológicas e bioquímicas, fornecendo assim, algumas informações básicas acerca do metabolismo desta espécie herbácea.

\section{MATERIAL E MÉTODOS}

O experimento foi desenvolvido na UNESP / Campus de Ilha Solteira, localizada a $20^{\circ} 43^{\prime} 09$ ' de latitude sul e 51³3'79' de longitude oeste, com altitude em torno de 335 metros, em casa de vegetação tipo Pad \& Fan, com duas irrigações diárias por aspersão controladas automaticamente, e temperatura máxima de $30^{\circ} \mathrm{C}$.

Foi utilizado como substrato um latossolo proveniente da Fazenda de Ensino, Pesquisa e Extensão da UNESP (FEPE), localizada no município de Selviria - MS, coletado na camada de $0-20 \mathrm{~cm}$. Esse solo foi seco ao ar e peneirado em malha de $4 \mathrm{~mm}$. Depois de homogeneizado, separou-se uma amostra do mesmo para análises químicas, Tabela 1. O solo foi corrigido de acordo com as recomendações técnicas para a cultura.

Tabela 1. Características químicas iniciais do solo utilizado no experimento, 0,0-0,20m, proveniente da Fazenda de Ensino, Pesquisa e Extensão da UNESP (FEPE), localizada no município de Selviria - MS, 2013.

\begin{tabular}{|c|c|c|c|c|c|c|c|c|}
\hline \multirow{2}{*}{$\begin{array}{l}P_{\text {resina }} \\
\mathrm{mg} / \mathrm{dm}^{3}\end{array}$} & M.O. & $\mathrm{pH}$ & K & $\mathrm{Ca}$ & $\mathrm{H}+\mathrm{Al}$ & $\mathrm{Al}$ & CTC & \multirow{2}{*}{$\begin{array}{l}\mathrm{V} \\
(\%)\end{array}$} \\
\hline & $\mathrm{g} / \mathrm{dm}^{3}$ & $\left(\mathrm{CaCl}_{2}\right)$ & \multicolumn{5}{|c|}{$\mathrm{mmol}_{\mathrm{c}} / \mathrm{dm}^{3}$} & \\
\hline 7 & 23 & 4,7 & 2,0 & 19 & 38 & 2 & 69,0 & 45 \\
\hline
\end{tabular}

Foram utilizados 40 vasos com capacidade de 15 litros de solo para o cultivo dos genótipos de algodoeiro FMT 701 e Fibermax 966. As sementes foram semeadas no dia 14 de fevereiro de 2014, a uma profundidade de $2 \mathrm{~cm}$ utilizando-se 4 sementes por vaso. $\mathrm{O}$ primeiro desbaste ocorreu aos 15 dias após a emergência (DAE), deixando duas plântulas Cultura Agronômica, Ilha Solteira, v.26, n.4, p.540-553, 2017 
por vaso, sendo escolhidas as de tamanho uniforme e bem distribuídas no recipiente. Aos 30 DAE realizou-se o segundo desbaste, ficando uma planta por vaso, totalizando 40 plantas. $\mathrm{O}$ cloreto de mepiquat foi pulverizado diretamente nas plantas e parcelado em três aplicações, realizadas aos 50, 60 e 70 DAE, cujos tratamentos foram ( 0,0 (testemunha); 500; 1,000; 1,500; e 2,500 $\mathrm{ml} \mathrm{ha}^{-1}$ ), equivalentes para o estudo em vasos. A altura das plantas foi medida aos 49 DAE, e em intervalos de 15 dias após a aplicação, até os 94 DAE, período em que foi conduzido o experimento, uma vez que não se avaliou os componentes de produção.

As avaliações da cinética de emissão da fluorescência máxima da clorofila $a$ foram realizadas aos 71 DAE, um dia após a última aplicação das doses de cloreto de mepiquat, tendo sido realizada simultaneamente às curvas A/DFFF com o fluorômetro portátil MultiMode Chlorophyll Fluorometer OS5p. Os parâmetros determinados foram: fluorescência inicial $\left(F_{0}\right)$, a fluorescência máxima $\left(F_{m}\right)$, a fluorescência variável $\left(F_{v}\right)$ e a eficiência fotoquímica do fotossistema II $\left(F_{v} / F_{m}\right)$. Os valores de $F_{m}$ e $F_{v}$, indicam, respectivamente, as fluorescências máxima e variável, determinadas após 30 minutos de adaptação ao escuro, e $F_{0}$ ' representa a florescência basal após a excitação do fotossistema I.

A fotossíntese em plantas pode ser descrita quantitativamente pelas curvas de $A / D F F F$ que discriminam alguns pontos, entre eles: capacidade fotossintética $\left(A_{\max }\right)$ e a eficiência quântica aparente $(E Q A)$ que corresponde à inclinação da região linear inicial da curva $A / D F F F$. A fotorrespiração $\left(F_{R}\right)$ foi calculada pelo modelo proposto para plantas de metabolismo C3 (SHARKEY, 1988). A $2^{\circ}$ e a $3^{\circ}$ folha adulta completamente expandida, do ápice do ramo de cada planta foi submetida a diferentes intensidades de $D F F F$, desde 2000 até $0 \mu \mathrm{mol} \mathrm{m} \mathrm{m}^{-2} \mathrm{~s}^{-1}$ durante 6 a 8 minutos, dependendo da velocidade de estabilização das leituras, sendo registradas as leituras ao final de cada etapa. Durante estas medições, a concentração de $\mathrm{CO}_{2}$ na câmara de amostragem do equipamento portátil de trocas gasosas, (Infra Red Gas Analyser -IRGA, marca ADC Bio Scientific Ltd, modelo LC-Pro) foi mantida em $380 \mu \mathrm{mol} \mathrm{mol}{ }^{-1}$, a temperatura da folha foi ajustada para $28{ }^{\circ} \mathrm{C}$. A luz para as curvas foi fornecida com uma fonte de LEDs de emissão no espectro do vermelho, acoplada a câmara de amostragem do Infra Red Gas Analyser -IRGA. As curvas de resposta $A / D F F F$ foram ajustadas de acordo com a equação de Prado e Moraes (1997), $A=A_{\operatorname{maxL}}\left(1-e^{-c(D F F F-}\right.$ ${ }^{P(o m L)}$ ), onde $A$ é a assimilação de $\mathrm{CO}_{2}$ momentânea; $A_{\max L}$ é capacidade fotossintética; $D F F F$ é a densidade de fluxo de fótons fotossintéticos momentâneo; e $P_{c o m L}$ é o ponto de compensação da fotossíntese à luz. As medidas foram realizadas aos $71 \mathrm{DAE}$, um dia após a última aplicação das doses de cloreto de mepiquat, das 8:00 as 13:00 h.

Para todas as análises fisiológicas e bioquímicas foram utilizadas somente folhas adultas, completamente expandidas, do ápice da planta ( $2^{\mathrm{a}}$ a $4^{\mathrm{a}}$ folha) sem sinais de senescência, da planta de cada vaso, coletadas aos 94 DAE. O material vegetal foi macerado em nitrogênio líquido, acondicionado em folhas de alumínio e armazenado no freezer a $-80^{\circ} \mathrm{C}$ para a realização das análises. Os extratos para as análises enzimáticas da superóxido dismutase (SOD), catalase (CAT) e peroxidase (POD) e para a análise da concentração de proteína, 
foram obtidos pela suspensão de $300 \mathrm{mg}$ do material vegetal moído em 5,0 mL de tampão fosfato de potássio $0,1 \mathrm{M}$, pH 6,8 contendo 0,1mM de EDTA $+3 \mathrm{mM}$ de DTT $+1 \%$ de carvão ativo. Após centrifugação por 10 minutos a $9000 \mathrm{rpm}$, a $4^{\circ} \mathrm{C}$, o sobrenadante foi coletado e armazenado no freezer a $-80^{\circ} \mathrm{C}$. Para cada enzima, utilizou-se um protocolo específico para determinar a atividade. Foi utilizado o método de Allain et al. (1974) e modificada por Lima et al. (1999) para a determinação de POD; a atividade da SOD foi determinada de acordo com o método de Beauchamp e Fridovich (1971) e a atividade da CAT foi mensurada através do método de Kar e Mishira (1976).

Os resultados das variáveis estudadas foram submetidos à análise de variância através do Teste $\mathrm{F}$ e as médias comparadas pelo teste de Tukey e no caso das doses de cloreto de mepiquat através da análise de regressão, de acordo com (GOMES, 2000). Utilizou-se o programa de análises estatísticas SISVAR (FERREIRA, 2000).

\section{RESULTADOS E DISCUSSÃO}

As médias de altura dos genótipos de algodoeiro herbáceo obtidas durante os períodos de permanência em casa de vegetação apresentaram diferenças significativas pelo teste de Tukey a 5\% de probabilidade, com média superior no FMT 701 na maioria das datas avaliativas, exceto aos 94 DAE (Tabela 2).

Houve interação entre as doses de cloreto de mepiquat $\mathrm{x}$ genótipos aos 64 DAE (Tabela 2.1) e de acordo com o desdobramento das equações obtidas, verificou-se que todas as doses de cloreto de mepiquat ocasionaram a diminuição da altura das plantas de ambos genótipos, porém no genótipo FMT 701 houve um ajuste quadrático dos valores médios, e de acordo com a equação obtida à dose calculada de $1302 \mathrm{~mL} \mathrm{ha}^{-1}$ foi a que mais reduziu o crescimento demasiado desse genótipo. No genótipo Fibermax 966 as doses que mais reduziram a altura foram as de $500 \mathrm{~mL} \mathrm{ha}^{-1}$ e $1000 \mathrm{~mL} \mathrm{ha}^{-1}$ respectivamente, não diferindo as médias dessas doses para esse genótipo. Não houve diferença significativa entre as médias dos genótipos em nenhuma das doses de cloreto de mepiquat aplicadas, apenas entre as plantas testemunhas, com a altura superior no FMT 701.

Pelo fato das plantas que não foram tratadas com o cloreto de mepiquat terem apresentado maiores médias de altura, comprova a tendência do regulador vegetal em reduzir o porte das plantas, pois este interfere na biossíntese do ácido giberélico, inibindo-o, o que resulta em redução do crescimento, em razão da menor elongação celular (LAMAS, 2001). Resultados semelhantes, com redução na altura de plantas com a aplicação de cloreto de mepiquat, foram verificados por vários autores, entre eles, (YORK, 1983; SOARES, 1999; BOGIANI; ROSOLEM, 2009). 
Tabela 2. Altura $(\mathrm{cm})$ de plantas de genótipos de algodoeiro herbáceo em diferentes dias após a emergência (DAE), em função de doses crescentes de cloreto de mepiquat. Ilha Solteira-SP, 2014.

\begin{tabular}{|c|c|c|c|c|}
\hline & 49 & 64 & 79 & 94 \\
\hline \multicolumn{5}{|l|}{ Genótipos } \\
\hline FMT 701 & $40,14 \mathrm{a}$ & $44,30 \mathrm{a}$ & $47,80 \mathrm{a}$ & $47,55 \mathrm{a}$ \\
\hline Fibermax 966 & $36,63 \mathrm{~b}$ & $41,78 \mathrm{~b}$ & $43,90 \mathrm{~b}$ & $45,10 \mathrm{a}$ \\
\hline \multicolumn{5}{|l|}{ Doses } \\
\hline 0 & 39,75 & 48,06 & 54,00 & 55,87 \\
\hline 500 & 37,87 & 41,75 & 43,00 & 43,25 \\
\hline 1000 & 38,37 & 39,75 & 43,87 & 43,50 \\
\hline 1500 & 38,00 & 41,75 & 42,37 & 43,37 \\
\hline 2500 & 38,37 & 44,25 & 46,00 & 45,62 \\
\hline \multicolumn{5}{|l|}{ TESTE F } \\
\hline Doses (d) & 0,841 & $0,001^{* *}$ & $0,001^{* *}$ & $0,001^{* *}$ \\
\hline Genótipos (g) & $0,004 * *$ & $0,037 *$ & $0,002 * *$ & 0,054 \\
\hline$d^{*} g$ & 0,117 & $0,022 *$ & 0,085 & 0,354 \\
\hline C.V(\%) & 9,28 & 8,44 & 7,89 & 8,32 \\
\hline Média geral & 38,47 & 43,11 & 45,85 & 46,32 \\
\hline $\mathrm{p}>\mathrm{F}$ (linear) & 0,579 & 0,201 & $0,002 * *$ & $0,001 * *$ \\
\hline $\mathrm{p}>\mathrm{F}$ (quadrática) & 0,434 & $0,001 * *(1)$ & $0,001 * *(2)$ & $0,001 * *(3)$ \\
\hline$r^{2}($ linear \%) & 22,49 & 6,97 & 20,25 & 25,47 \\
\hline $\mathrm{r}^{2}$ (quadrática\%) & 67,49 & 85,62 & 82,38 & 80,22 \\
\hline \multicolumn{5}{|c|}{ Equações Polinomiais } \\
\hline \multirow{3}{*}{\multicolumn{5}{|c|}{$\begin{array}{l}\text { (1) } Y=0,000004 x^{2}-0,010381 x+47,236469 \\
\text { (2) } Y=0,000005 x^{2}-0,014807 x+52,481222 \\
\text { (3) } Y=0,000005 x^{2}-0,016321 x+53,936672\end{array}$}} \\
\hline & & & & \\
\hline & & & & \\
\hline
\end{tabular}

Médias seguidas pela mesma letra na vertical não diferem entre si pelo teste de Tukey a 5\% de probabilidade. **, * Significativo aos níveis de $1 \%$ e $5 \%$ respectivamente pelo Teste F.

Pelo resultado exposto na Tabela 2.1, ficou evidente que para o genótipo Fibermax 966 de porte baixo e ciclo precoce, a dose de menor concentração é capaz de reduzir a altura das plantas, uma vez que apresenta uma estrutura mais compacta exige menor uso de regulador de crescimento. Este resultado está de acordo com Bogiani e Rosolem (2009), segundo ele a sensibilidade ao cloreto de mepiquat é maior em cultivares mais precoces. Por outro lado, no genótipo FMT 701 de porte alto e ciclo médio tardio foi necessário a dose superior para reduzir a altura. Isso é devido ao porte que ambos possuem, ou seja, para o controle da altura das plantas altas foi necessário à aplicação da dose mais concentrada do que a aplicada nas plantas de porte baixo. Além disso, também foi possível constatar que o cloreto de mepiquat teve um efeito mais pronunciado em reduzir a altura do genótipo FMT 701 , obtendo a menor média de altura calculada $(39,9 \mathrm{~cm})$, ou seja, o efeito mais positivo do regulador de crescimento se dá em genótipos de porte e ciclo mais longo (LAMAS, 2001). 
Tabela 2.1. Desdobramento da interação de doses de cloreto de mepiquat $\mathrm{x}$ genótipos referente à altura de plantas aos 64 DAE. Ilha Solteira-SP, 2014.

\begin{tabular}{ccc}
\hline Fatores & Genótipos \\
\hline Doses de regulador & FMT 701 \\
$\left(\mathrm{mL} \mathrm{ha}^{-1}\right)$ & $52,60 \mathrm{a}$ & Fibermax 966 \\
0 & $43,25 \mathrm{a}$ & $43,62 \mathrm{~b}$ \\
500 & $39,25 \mathrm{a}$ & $40,25 \mathrm{a}$ \\
1000 & $40,70 \mathrm{a}$ & $40,25 \mathrm{a}$ \\
1500 & $46,75 \mathrm{a}$ & $43,50 \mathrm{a}$ \\
2500 & 0,097 & $41,75 \mathrm{a}$ \\
\hline $\mathrm{p}>\mathrm{F}$ (linear) & $0,001 * *(1)$ & 0,932 \\
$\mathrm{p}>\mathrm{F}$ (quadrática) & 8,34 & 0,570 \\
$\mathrm{r}^{2}$ (linear \%) & 95,71 & 0,24 \\
$\mathrm{r}^{2}$ (quadrática\%) & ${ }^{(1)} \mathrm{Y}=0,000007 \mathrm{x}^{2}-0,018232 \mathrm{x}+51,774227$ \\
\hline
\end{tabular}

Médias seguidas da mesma letra, na linha, não diferem entre si pelo teste de Tukey, em nível de 5\% de probabilidade. ${ }^{*}, *$ Significativo aos níveis de $1 \%$ e $5 \%$ respectivamente pelo Teste F.

Tabela 3. Fluorescência inicial $\left(F_{0}\right)$, fluorescência máxima $\left(F_{m}\right)$, fluorescência variável $\left(F_{v}\right)$ e eficiência quântica $\left(F_{v} / F_{m}\right)$, em genótipos de algodoeiro herbáceo em função de doses crescentes de cloreto de mepiquat. Ilha Solteira-SP, 2014.

\begin{tabular}{ccccc}
\hline & $F_{0}$ & $F_{m}$ & $F_{v}$ & $F_{v} / F_{m}$ \\
\hline Genótipos & & & & \\
FMT 701 & $0,21 \mathrm{a}$ & $0,31 \mathrm{a}$ & $0,57 \mathrm{a}$ & $0,74 \mathrm{a}$ \\
Fibermax 966 & $0,19 \mathrm{a}$ & $0,35 \mathrm{a}$ & $0,57 \mathrm{a}$ & $0,78 \mathrm{~b}$ \\
\hline Doses & & & & \\
0 & 0,20 & 0,33 & 0,63 & 0,78 \\
500 & 0,19 & 0,30 & 0,48 & 0,76 \\
1000 & 0,20 & 0,32 & 0,57 & 0,76 \\
1500 & 0,22 & 0,31 & 0,60 & 0,73 \\
2500 & 0,20 & 0,38 & 0,57 & 0,74 \\
\hline TESTE F & & $\mathrm{p}>\mathrm{F}$ & & \\
Doses (d) & 0,566 & 0,405 & 0,082 & 0,484 \\
Genótipos (g) & 0,099 & 0,086 & 0,861 & $0,037 *$ \\
d*g & 0,559 & 0,126 & 0,182 & 0,997 \\
C. V(\%) & 19,93 & 24,96 & 15,76 & 7,71 \\
Média geral & 0,20 & 0,33 & 0,57 & 0,76 \\
\hline p $>$ F (linear) & 0,491 & 0,183 & 0,915 & 0,597 \\
p $>$ F (quadrática) & 0,763 & 0,159 & 0,451 & 0,137 \\
r $^{2}$ (linear \%) & $16,25 \%$ & $44,97 \%$ & $0,13 \%$ & $8,05 \%$ \\
$\mathrm{r}^{2}$ (quadrática\%) & $19,34 \%$ & $95,59 \%$ & $6,91 \%$ & $74,17 \%$ \\
\hline
\end{tabular}

Médias seguidas pela mesma letra na vertical não diferem entre si pelo teste de Tukey a $5 \%$ de probabilidade. **, * Significativo aos níveis de $1 \%$ e $5 \%$ respectivamente pelo Teste $\mathrm{F}$.

Pelos dados apresentados na Tabela 3 constatou-se que nenhuma das variáveis analisadas que avaliam a eficiência do aparato fotossintético de genótipos de algodoeiro foram afetadas pelas doses crescentes de cloreto de mepiquat, mostrando que a superdose do 
princípio ativo utilizado não ocasionou danos ao aparato fotoquímico e nas características da fluorescência da clorofila $a$ do algodoeiro.

De acordo com Lichtenthaler e Miehé (1997), Maxwell e Johnson (2000) a energia luminosa usada na fotossíntese pode ser dissipada como calor, e/ou reemitida como luz de longo comprimento de ondas, sendo este último processo conhecido como fluorescência.

A fluorescência inicial $\left(F_{0}\right)$, a fluorescência máxima da clorofila $a\left(F_{m}\right)$ e a fluorescência variável $\left(F_{v}\right)$ não diferiram entre os genótipos. Segundo Krause e Weiss (1991) a fluorescência inicial $\left(F_{0}\right)$ representa a fluorescência com todos os centros de reação abertos e refere-se à emissão da fluorescência pelas moléculas de clorofila $a$ do complexo coletor de luz do fotossistema II (FSII). De acordo com Björkman e Demming (1987) a fluorescência máxima $\left(F_{m}\right)$ indica a completa redução da quinona $\mathrm{A}\left(\mathrm{Q}_{\mathrm{A}}\right)$ a partir da incidência de um pulso de luz no centro de reação $\mathrm{Q}_{\mathrm{A}}$, gerando fluorescência máxima. $\mathrm{A}$ diferença entre $\left(F_{m}\right)$ e $\left(F_{0}\right)$ resulta na fluorescência variável $\left(F_{v}\right)$. A $F_{v}$ representa o fluxo de elétrons do centro de reação do FSII (P680) até a plastoquinona $\left(\mathrm{PQH}_{2}\right)$. A fluorescência da clorofila $a$ pode ser usada para estimar a eficiência do transporte de elétrons através do fotossistema II (FSII), e a eficiência de operação deste fotossistema está correlacionado a assimilação de $\mathrm{CO}_{2}$ (MOUGET; TREMBLIN, 2002).

Os resultados obtidos no presente experimento sugerem que os genótipos apresentam à mesma capacidade de dissipação da fluorescência máxima da clorofila $a\left(F_{m}\right)$, ou seja, isso implica na mesma eficiência em reduzir a $Q_{A}$ e a mesma eficiência do transporte de elétrons e de assimilação do $\mathrm{CO}_{2}$. Houve diferença significativa entre os genótipos com relação à eficiência quântica potencial do FSII $\left(F_{v} / F_{m}\right)$, sendo a média superior no genótipo Fibermax $966(5,12 \%)$.

Segundo Posada et al. (2011) a relação $F_{\Downarrow} / F_{m}$ caracteriza a eficiência fotoquímica dos genótipos e indica pleno funcionamento do aparato fotossintético das plantas. Assim, o aumento da eficiência quântica do FSII indica melhor aproveitamento e conversão da energia luminosa. Ou seja, o resultado obtido no presente experimento sugere que o genótipo Fibermax 966 teve melhor aproveitamento na conversão da energia luminosa, pois apresentou maior eficiência quântica do FSII. Foi possível constatar que as médias de $F_{v} / F_{m}$ variaram de 0,73 a 0,78, estando de acordo com os resultados obtidos por Li et al. (2004) que estudaram a relação $F_{\Downarrow} / F_{m}$ para 99 espécies nativas com diferentes habitats da região da Mongólia e neste estudo encontraram valores entre 0,57 a 0,79 , com média 0,76 , em função do tipo de planta, mecanismo fisiológico e local de crescimento, relatando para plantas C3 um valor médio de 0,72. De acordo com Critchley (1998) em valores abaixo de 0,725, as folhas certamente foram submetidas ao dano fotoinibitório. Ou seja, pode-se afirmar com base no relato acima que as folhas dos genótipos de algodoeiro do presente experimento não foram submetidas à fotoinibição, pois os valores foram superiores a 0,725.

Conforme Long et al. (1994) a fotoinibição é um processo fisiológico caracterizado pela redução lenta e reversível da fotossíntese como resultado da exposição à luz solar

Cultura Agronômica, Ilha Solteira, v.26, n.4, p.540-553, 2017 
plena. A intensidade da fotoinibição pode ser avaliada pela redução na eficiência quântica do FSII, ou seja, pela relação $F_{v} / F_{m}$. Sendo assim, a fotoinibição é utilizada como um indicador de estresse nas plantas, quando fatores bióticos ou abióticos alteram a funcionalidade do FSII. É importante salientar que o dano da luz ao FSII é considerado fotoinibição, por definição, se ocorrer decréscimo em toda capacidade fotossintética e não apenas em um componente do aparato fotossintético, sendo que a fotoinibição não é um fenômeno localizado. Dessa forma, pressupõe-se que o cloreto de mepiquat não ocasionou o estresse no aparato fotoquímico dos genótipos.

Tabela 4. Valores médios da capacidade fotossintética líquida $\left(A_{\operatorname{maxL}}-\mu m o l \mathrm{CO}_{2} \mathrm{~m}^{-2} \mathrm{~s}^{-1}\right)$, fotorrespiração $\left(F_{R}-\mu m o l C_{2} m^{-2} s^{-1}\right)$ e eficiência quântica aparente de $\mathrm{CO}_{2}(E Q A)$, em genótipos de algodoeiro herbáceo em função de doses crescentes de cloreto de mepiquat, obtidos da curva A/DFFF aos 71 (DAE). Ilha Solteira-SP, 2014.

\begin{tabular}{ccll}
\hline & $A_{\max L}$ & $F_{R}$ & $E Q A$ \\
\hline Genótipos & & & \\
FMT 701 & $4,81 \mathrm{a}$ & $2,54 \mathrm{a}$ & $0,75 \mathrm{a}$ \\
Fibermax 966 & $5,33 \mathrm{a}$ & $2,42 \mathrm{a}$ & $0,76 \mathrm{a}$ \\
\hline Doses & & & \\
0 & 4,86 & 2,39 & 0,77 \\
500 & 6,50 & 2,00 & 0,75 \\
1000 & 4,52 & 3,15 & 0,76 \\
1500 & 4,56 & 2,48 & 0,75 \\
2500 & 4,93 & 2,37 & 0,76 \\
\hline TESTE F & & $\mathrm{p}>\mathrm{F}$ & \\
Doses (d) & $0,009^{* *}$ & $0,001^{* *}$ & 0,352 \\
Genótipos (g) & 0,109 & 0,180 & 0,130 \\
d*g & 0,064 & 0,056 & 0,133 \\
C.V(\%) & 13,12 & 7,77 & 2,01 \\
Média geral & 5,07 & 2,48 & 0,76 \\
\hline p>F (linear) & 0,158 & 0,076 & 0,573 \\
p>F(quadrática) & 0,672 & 0,575 & 0,273 \\
r (linear \%) & $9,67 \%$ & $5,30 \%$ & $6,82 \%$ \\
r $^{2}$ (quadrática\%) & $10,4 \%$ & $5,76 \%$ & $33,8 \%$ \\
\hline
\end{tabular}

Para análise, os dados foram transformados em $(x+0,5)^{1 / 2}$. Médias seguidas pela mesma letra na vertical não diferem entre si pelo teste de Tukey a $5 \%$ de probabilidade. ${ }^{* *}$, * Significativo aos níveis de $1 \%$ e $5 \%$ respectivamente pelo Teste $\mathrm{F}$.

De acordo com os dados obtidos no ponto de saturação à luz nos genótipos de algodoeiro aos 71 DAE (Tabela 4), foi possível constatar que as doses de cloreto de mepiquat influenciaram significativamente a fotorrespiração $\left(F_{R}\right)$ e a capacidade fotossintética líquida $\left(A_{\max L}\right)$. Quanto à capacidade fotossintética líquida $\left(A_{\max L}\right)$, a média não diferiu entre os genótipos, e as doses de $500 \mathrm{ml} \mathrm{ha}^{-1}$ e $2500 \mathrm{ml} \mathrm{ha}^{-1}$ promoveram o aumento da capacidade fotossintética líquida $\left(A_{\max L}\right)$ dos genótipos, enquanto que as doses de $1000 \mathrm{ml} \mathrm{ha}^{-1}$ e $1500 \mathrm{ml} \mathrm{ha}^{-1}$ reduziram. A fotorrespiração $\left(F_{R}\right)$ também não diferiu entre os genótipos, e as doses de $1000 \mathrm{ml} \mathrm{ha}^{-1}$ e $1500 \mathrm{ml} \mathrm{ha}^{-1}$ aumentaram a fotorrespiração $\left(F_{R}\right)$ e as doses de $500 \mathrm{ml} \mathrm{ha}^{-1}$ e $2500 \mathrm{ml} \mathrm{ha}^{-1}$ reduziram.

Cultura Agronômica, Ilha Solteira, v.26, n.4, p.540-553, 2017 
Embora o genótipo Fibermax 966 tenha apresentado melhor aproveitamento na conversão da energia luminosa, pois apresentou maior eficiência quântica do FSII $\left(F_{v} / F_{m}\right)$ Tabela 3 , esse fato não se refletiu na capacidade fotossintética líquida $\left(A_{\operatorname{maxL}}\right)$, visto que a média entre os genótipos não diferiu significativamente.

Segundo Raven et al. (2007) a diferença entre a fotossíntese bruta e a respiração denomina-se fotossíntese líquida. Sendo assim, a fotossíntese liquida é a energia que sobra desse processo. Na presença de luz, o processo chamado de fotorrespiração corresponde à perda de $\mathrm{CO}_{2}$ (liberação) e consumo de $\mathrm{O}_{2}$. Tal processo ocorre apenas em tecidos verdes em condições de altos níveis de luminosidade e temperatura. Esse processo pode reduzir em até 50 a $60 \%$ a fotossíntese líquida.

Hodges (1991) em sua pesquisa com algodoeiro, relatou que as doses de cloreto de mepiquat influenciaram o crescimento, a fotossíntese e a respiração das plantas. Segundo este autor, a fotossíntese parece ter maior eficiência em função da redução da fotorrespiração em plantas tratadas com o cloreto de mepiquat. Como verificou-se na Tabela 4 , as doses de cloreto de mepiquat que reduziram a fotorrespiração $\left(F_{R}\right)$ nos genótipos de algodoeiro, promoveram o aumento da capacidade fotossintética líquida $\left(A_{\max L}\right)$, e viceversa, corroborando com o relato desse autor.

Quanto a eficiência quântica aparente de assimilação do $\mathrm{CO}_{2}(E Q A)$, Tabela 4, não houve diferença entre os genótipos e as doses não foram significativas. A eficiência quântica aparente de assimilação do $\mathrm{CO}_{2}(E Q A)$ não ter diferido entre os genótipos explica por que a capacidade fotossintética líquida $\left(A_{\operatorname{maxL}}\right)$ entre os genótipos não diferiu significativamente. Pelo fato da EQA não ter sido influenciada pelas doses de cloreto de mepiquat, possivelmente o produto não provocou danos ao aparato fotoquímico dos genótipos. Esse resultado está de acordo com os dados obtidos da fluorescência da clorofila $a$, Tabela 3 , no qual a razão da eficiência quântica potencial do FSII $\left(F_{v} / F_{m}\right)$ que indica o bom funcionamento do aparato fotoquímico também não foi influenciado pelas doses de cloreto de mepiquat e o resultado revelou que os genótipos não tiveram o aparato fotoquímico sob estresse.

Na Tabela 5 estão os dados referentes à atividade das enzimas do sistema antioxidante catalase (CAT), peroxidase (POD) e superóxido dismutase (SOD). Foi possível constatar que as doses de cloreto de mepiquat não provocaram variação na atividade das enzimas, o que demonstra ausência de resposta do sistema antioxidativo, ou seja, a superdosagem de regulador de crescimento não ocasionou danos para que o aparato enzimático da planta fosse acionado. Também não houve diferença da atividade enzimática entre os genótipos, indicando o mesmo comportamento em relação ao sistema antioxidante.

De acordo com Souza et al. (2005) a condição de desequilíbrio entre a atividade fotoquímica e bioquímica da fotossíntese favorece a geração de espécies reativas de oxigênio (EROs), o que resulta segundo Cavalcanti et al. (2004) numa maior demanda por um eficiente mecanismo antioxidante de defesa para evitar o estresse oxidativo. Dessa

Cultura Agronômica, Ilha Solteira, v.26, n.4, p.540-553, 2017 
forma, estima-se que embora a fotossintética líquida $\left(A_{\max L}\right)$ e a fotorrespiração $\left(F_{R}\right)$ (Tabela $4)$, tenham sido influenciados pelas doses de cloreto de mepiquat, bem como o crescimento em altura dos genótipos de algodoeiro (Tabela 2), ocorreu uma resposta positiva, não levando a formação das espécies reativas de oxigênio (EROs), sendo desnecessário então a ativação das enzimas antioxidantes, catalase (CAT), peroxidase (POD) e superóxido dismutase (SOD).

Tabela 5. Atividade das enzimas antioxidantes catalase (CAT: umol $\mathrm{H}_{2} \mathrm{O}_{2}$ decomposto min ${ }^{1} \mathrm{mg}$ de proteína ${ }^{-1}$ ), peroxidase (POD: umol de $\mathrm{H}_{2} \mathrm{O}_{2}$ decomposto $\mathrm{min}^{-1} \mathrm{mg}$ de proteína ${ }^{-1}$ ) e superóxido dismutase (SOD: Unidade $\mathrm{mg}$ de proteína $^{-1}$ ), em genótipos de algodoeiro herbáceo em função de doses crescentes de cloreto de mepiquat. Ilha Solteira-SP, 2014.

\begin{tabular}{|c|c|c|c|}
\hline & \multicolumn{3}{|c|}{ ENZIMAS ANTIOXIDANTES } \\
\hline & $\begin{array}{c}\text { CAT } \\
(\mathrm{EC} 1.11 .1 .6)\end{array}$ & $\begin{array}{c}\text { POD } \\
(\mathrm{EC} 1.11 .1 .6)\end{array}$ & $\begin{array}{c}\text { SOD } \\
(\mathrm{EC} 1.15 .1 .1)\end{array}$ \\
\hline \multicolumn{4}{|l|}{ Genótipos } \\
\hline FMT 701 & $2,68 \times 10^{-10} \mathrm{a}$ & $6,67 \times 10^{-3} \mathrm{a}$ & $209,31 \mathrm{a}$ \\
\hline Fibermax 966 & $2,38 \times 10^{-10} \mathrm{a}$ & $7,12 \times 10^{-3} \mathrm{a}$ & $257,31 \mathrm{a}$ \\
\hline \multicolumn{4}{|l|}{ DOSES } \\
\hline 0 & $2,40 \times 10^{-10}$ & $5,85 \times 10^{-3}$ & 225,60 \\
\hline 500 & $2,28 \times 10^{-10}$ & $7,61 \times 10^{-3}$ & 227,78 \\
\hline 1000 & $3,08 \times 10^{-10}$ & $8,82 \times 10^{-3}$ & 224,97 \\
\hline 1500 & $2,28 \times 10^{-10}$ & $7,50 \times 10^{-3}$ & 249,56 \\
\hline 2500 & $2,64 \times 10^{-10}$ & $4,70 \times 10^{-3}$ & 238,65 \\
\hline TESTE F & & $\mathrm{p}>\mathrm{F}$ & \\
\hline Doses (d) & 0,833 & 0,349 & 0,995 \\
\hline Genótipos(g) & 0,552 & 0,738 & 0,290 \\
\hline$d^{*} g$ & 0,725 & 0,342 & 0,593 \\
\hline C.V(\%) & 32,19 & 31,84 & 30,47 \\
\hline Média geral & $2,53 \times 10^{-10}$ & $6,89 \times 10^{-3}$ & 233,31 \\
\hline $\mathrm{p}>\mathrm{F}$ (linear) & 0,793 & 0,433 & 0,783 \\
\hline $\mathrm{p}>\mathrm{F}$ (quadrática) & 0,831 & 0,063 & 0,923 \\
\hline $\mathrm{r}^{2}($ linear $\%)$ & $4,84 \%$ & $13,66 \%$ & $42,32 \%$ \\
\hline $\mathrm{r}^{2}$ (quadrática $\left.\%\right)$ & $8,06 \%$ & $94,52 \%$ & $47,61 \%$ \\
\hline
\end{tabular}

Médias seguidas pela mesma letra na vertical não diferem entre si pelo teste de Tukey a 5\% de probabilidade.

\section{CONCLUSÃO}

A aplicação foliar de cloreto de mepiquat reduziu o crescimento em altura dos genótipos de algodoeiro herbáceo, sendo o efeito mais positivo do regulador vegetal no FMT 701 de porte alto e ciclo mais longo.

O genótipo Fibermax 966 de porte baixo e ciclo precoce exigiu menor uso de regulador vegetal, tendo seu crescimento em altura mais reduzido com as doses de menor concentração. 
As doses de cloreto de mepiquat influenciaram a taxa de fotossíntese líquida e a fotorrespiração dos genótipos, sendo que estes apresentaram a mesma eficiência de assimilação do $\mathrm{CO}_{2}$.

O cloreto de mepiquat não ocasionou danos ao aparato fotoquímico, nas características da fluorescência da clorofila $a$ e não acionou a atividade das enzimas antioxidantes dos genótipos, não desencadeando o estresse oxidativo.

\section{AGRADECIMENTOS}

À CAPES (Coordenação de Aperfeiçoamento de Pessoal de Nível Superior) pela concessão da bolsa.

\section{REFERÊNCIAS BIBLIOGRÁFICAS}

ALlAIN, C. C.; POON, L. S.; CHAN, C. S. G.; RICHMOND, W.; FU, P. C. Enzymatic determination of total serum cholesterol. Clinical Chemistry, Baltimore, v. 20, n. 4, p.470475, 1974.

APEL, K.; HIRT, H. Reactive oxygen species: metabolism, oxidative stress and signal transduction. Annual Review of Plant Biology, Palo Alto, v. 55, n. 2, p.373-99, 2004.

BAYER CROPSCIENCE. Sementes fibermax: FMX 966. São Paulo: [s.n.], 2012. Disponível em: http://www.certificacaofibermax.com.br . Acesso em: 30 jan. 2013

BEAUCHAMP, C.; FRIDOVICH, I. Superoxide dismutase: improved assays and applicable to acrylamide gels. Analytical Biochemistry, Maryland, v. 44, n. 1, p.276-287, 1971.

BELTRÃO, N. E. M.; AZEVEDO, D. M. P.; VIEIRA, D. J.; NÓBREGA L. B. Recomendações técnicas e considerações gerais sobre o uso de herbicidas, desfolhantes e reguladores de crescimento na cultura do algodão. Campina Grande: EMBRAPA CNPA, 1997. 32 p. (Documentos, 48).

BJÖRKMAN, O.; DEMMING, B. Photon yield of $\mathrm{O}_{2}$ evolution and chlorophyll fluorescence characteristics at $77 \mathrm{k}$ among vascular plants of diverse origins. Planta, Heidelberg, v. 170, n. 4, p.61-66, 1987.

BOGIANI, J. C.; ROSOLEM, C. A. Sensibilidade de cultivares de algodoeiro ao cloreto de mepiquat. Pesquisa Agropecuária Brasileira, Brasília, v.44, n. 10, p.1246-1253, 2009.

CAVAlCANTI, F. R.; OLIVEIRA, J. T. A.; MARTINS-MIRANDA, A. S.; VIEGAS, R. A.; SILVEIRA, J. A. G. Superoxide dismutase, catalase and peroxidase activities do not confer protection against oxidative damage in salt-stressed cowpea leaves. New Phytologist, Lancaster, v. 163, n. 3, p. 563-71, 2004.

CRITCHLEY, C. Photoinhibition. In: RAGHAVENDRA, A. S. (Ed.). Photosynthesis: A comprehensive treatise. Cambridge: Cambridge University Press, 1998. cap. 20, p. 264-272.

Cultura Agronômica, Ilha Solteira, v.26, n.4, p.540-553, 2017 
FERNANDEZ, C. J.; COTHREN, J. T.; McINNES, K. J. Partitioning of biomass in wellwatered and water-stressed cotton plants treated with mepiquat chloride. Crop Science, Madison, v. 31, n. 5, p.1224-1228, 1991.

FERREIRA, D. F. Análises estatísticas por meio do SISVAR para Windows versão 4.0. In: REUNIÃO ANUAL DA REGIÃO BRASILEIRA DA SOCIEDADE INTERNACIONAL DE BIOMETRIA, 45., 2000, São Carlos. Anais... São Carlos: UFSCar, 2000. p. 255-258.

FUNDAÇÃO MT. Cultivares convencionais: FMT 701. Cuiabá: [s.n.], 2012. Disponível em: http://www.fundacaomt.com.br/algodao/cult.php?t=1\&tipo=fmt701. Acesso em: 15 out. 2013.

GOMES, F. P. Curso de estatística experimental. 14. ed. Piracicaba: USP, 2000. 477 p.

HODGES, H. F.; REDDY, V. R.; REDDY, K. R. Mepiquat chloride and temperature effects on photosynthesis and respiration of fruiting cotton. Crop Science, Madison, v. 31, n. 5, p.1301-1308, 1991.

KAR, M.; MISHRA, D. Catalase, peroxidase and polyphenoloxidase activities during rice leaf senencence. Plant Physiology, New York, v. 57, n. 2, p.315- 319, 1976.

KRAUSE, G. H.; WEIS, E. Chlorophyll fluorescence and photosynthesis: the basics. Annual Review Plant Physiology. Plant Molecular Biology, Palo Alto, v. 42, n. 2, p.313349, 1991.

LAMAS, F. M. Estudo comparativo entre cloreto de mepiquat e cloreto de chlormequat aplicados em algodoeiro. Pesquisa Agropecuária Brasileira, Brasilia, v. 36, n. 2, p.265272, 2001.

LI, Y. G; LI, L. H; JIANG, G. M. Traits of chlorophyll fluorescence in 99 plants species from the sparse-elm grassland in Hunshandak Sandland. Photosynthetica, Prague, v. 42, n. 2, p.243-249, 2004.

LICHTENTHALER, H. K.; MIEHÉ, J. A. Fluorescence imaging as a diagnostic tool for plant stress. Trends Plant Science, London, v. 2, n. 8, p.316-320, 1997.

LIMA, G. P. P.; BRASIL, O. G.; OLIVEIRA, A. M. Poliaminas e atividade da peroxidase em feijão (Phaseolus vulgaris L.) cultivado sob estresse salino. Scientia Agricola, Piracicaba, v. 56, n. 1, p.21-25, 1999.

LONG, S. P.; HUMPHRIES, S.; FALKOWSKI, P. G. Photoinhibition of photosynthesis in nature. Annual Review of Plant Physiology and Plant Molecular Biology, Palo Alto, v. 45, n. 1, p. 633-662, 1994.

MAXWELL, K.; JOHNSON, G. N. Chlorophyll fluorescence - a practical guide. Journal of Experimental Botany, Oxford, v. 51, n. 345, p.659-668, 2000.

Cultura Agronômica, Ilha Solteira, v.26, n.4, p.540-553, 2017 
MOUGET, J.; TREMBLIN, G. Suitability of the fluorescence monitoring system (FM, Hansatech) for measurement of photosynthetic characteristics in algae. Aquatic Botany, Amsterdan, v. 74, n. 3, p.219-231, 2002.

PRADO, C. H. B. A.; MORAES, J. A. P. V. Photosynthetic capacity and specific leaf mass in twenty woody species of cerrado vegetation under field conditions. Photosynthetica, Prague, v. 33, n. 1, p. 103-112, 1997.

POSADA, F. C.; OLMOS, J. E. P.; ULRICHS, C. Crecimiento y eficiencia fotoquímica del fotosistema II en plantas de fresa (Fragaria sp.) afectadas por la calidad de la luz: Implicaciones agronómicas. Revista U. D. C. - A Actualidad \& Divulgación Científica, Bogotá, v. 14, n. 2, p.43-53, 2011.

RAVEN, P. H.; EVERT, R. F.; EICHHORN, S. E. Biologia vegetal. 7. ed. Rio de Janeiro: Guanabara Koogan, 2007. 830 p.

REDDY, K. R.; BOONE, M. L.; REDDY, A. R.; HODGES, H. F.; TURNER, S. B.; McKINION, J.M. Developing and validating a model for a plant growth regulador. Agronomy Journal, Madison, v. 87, n. 6, p.1100-5, 1995.

SHARKEY, T. D. Estimating the rate of photorespiration in leaves. Physiologia Plantarum, v. 73, p.147-152, 1988.

SOARES, J. J. Fitorreguladores e remoção da gema apical no desenvolvimento do algodoeiro. Scientia Agricola, Piracicaba, v. 56, n. 3, p.627-630, 1999.

SOUZA, R. P.; RIBEIRO, R, V.; MACHADO, E.C.; OLIVEIRA, R.F.; SILVEIR, J.A.G. Photosynthetic responses of young cashew plants to varying environmental conditions. Pesquisa Agropecuária Brasileira, v. 40, n. 8, p.735-744, 2005.

TAIZ, L.; ZEIGER, E. Fisiologia vegetal. 5. ed. Porto Alegre: ArtMed, 2013. 954 p.

YORK, A. C. Cotton cultivar response to mepiquat chloride. Agronomy Journal, Madison, v. 75, n. 4, p.663-667, 1983. 